\title{
Genome Editing with CRISPR-Cas9 Systems: Basic Research and Clinical Applications
}

\author{
Anna Meiliana ${ }^{1,2, *}$, Nurrani Mustika Dewi ${ }^{1,2}$, Andi Wijaya ${ }^{1,2,3}$ \\ ${ }^{1}$ Postgraduate Program in Clinical Pharmacy, Padjadjaran University, Jl. Eijkman No.38, Bandung, Indonesia \\ ${ }^{2}$ Prodia Clinical Laboratory, J1. Cisangkuy No.2, Bandung, Indonesia \\ ${ }^{3}$ Postgraduate Program in Clinical Biochemistry, Hasanuddin University, Jl. Perintis Kemerdekaan Km.10, Makassar, Indonesia \\ *Corresponding author. E-mail: anna.meiliana@prodia.co.id
}

Received date: Oct 31, 2016; Revised date: Mar 16, 2017; Accepted date: Mar 21, 2017

\section{Abstract}

$\mathrm{B}$

ACKGROUND: Recently established genome editing technologies will open new avenues for biological research and development. Human genome editing is a powerful tool which offers great scientific and therapeutic potential.

CONTENT: Genome editing using the clustered regularly interspaced short palindromic repeats (CRISPR)/CRISPRassociated protein 9 (Cas9) technology is revolutionizing the gene function studies and possibly will give rise to an entirely new degree of therapeutics for a large range of diseases. Prompt advances in the CRISPR/Cas9 technology, as well as delivery modalities for gene therapy applications, are dismissing the barriers to the clinical translation of this technology. Many studies conducted showed promising results, but as current available technologies for evaluating off-target gene modification, several elements must be addressed to validate the safety of the CRISPR/Cas9 platform for clinical application, as the ethical implication as well.

SUMMARY: The CRISPR/Cas9 system is a powerful genome editing technology with the potential to create a variety of novel therapeutics for a range of diseases, many of which are currently untreatable.

KEYWORDS: genome editing, CRISPR-Cas, guideRNA, DSB, ZFNs, TALEN

Indones Biomed J. 2017; 9(1): 1-16

\section{Introduction}

In the 1970s, a new horizon in Biology era was started. Through the recombinant DNA development, molecular biologist made it possible to study genes and manipulate DNA molecules for the 1st time, harness them to developed more advanced medicine and biotechnology. Researchers now cannot separate the study of DNA from genome context. DNA sequences can be directly edited to modulate their function in endogenous context virtually, and this can be applied to any organism of choice, allowing them to elucidate the functional organization of the genome at the systems level and also identify causal genetic variations.(1)
Eukaryotic genomes contain billions of DNA bases and are not prone to manipulate. One of the breakthroughs in genome manipulation is the development of gene targeting by homologous recombination (HR) that integrates exogenous repair templates that contain sequence homology to the donor site.(2) HR-mediated targeting has facilitated the generation of knocking and knockout animal models via manipulation of germline-competent stem cells, dramatically advancing numerous areas of biological research.

Genome engineering generally refers to the process, the contexts (e.g., epigenetic marks), or the outputs (e.g., transcripts) of targeted modifications of genomes. Efficient and easy to do in eukaryotic and specific mammalian cells, 
this ability holds enormous, not only promise but also challenges to transform basic science, biotechnology and medicine. Therefore, a series of programmable nucleasebased genome editing have been developed to enable this genome engineering, particularly in mammalian species. CRISPR-associated protein 9 (Cas9), an RNA-guided endonuclease from microbial adaptive immune system clustered regularly interspaced short palindromic repeats (CRISPR), is the most rapidly developing among the current generation of genome editing technologies, which can be easily virtually targeted to any genomic location of choice by a short RNA guide.(1)

Studies by Haber and Jasin led to the realization that targeted DNA double-strand break (DSB) could largely stimulate genome editing through HR-mediated recombination events.(3-8) Subsequently, Carroll and Chandrasegaran showed the potential of designer nucleases based on zinc finger proteins for efficient, locus-specific HR. $(7,8)$ Moreover, it was presented in the absence of an exogenous homology repair template which localized DSBs can cause insertions or deletion mutations (indels) via the error-prone nonhomologous end-joining (NHEJ) repair pathway.(9) These early genome editing studies built DSB-induced HR and NHEJ as powerful pathways for the versatile and precise modification of eukaryotic genomes. There are four major classes of customizable DNA-binding proteins that have been engineered so far. To achieve effective genome editing via introduction of site-specific DNA DSBs, such as meganucleases derived from microbial mobile genetic elements (10) zinc-finger nucleases (ZFNs) based on eukaryotic transcription factors $(11,12)$, transcription activator-like effectors (TALEs) from Xanthomonas bacteria (13-16) and very recently the RNAguided DNA endonuclease Cas9 from the type II bacterial adaptive immune system CRISPR $(17,18)$.

New modes of recognition with simplification of custom nucleases development were needed to answer the challenges associated with the engineering of modular DNA-binding proteins. A short guide RNA, via WatsonCrick base pairing recognizing the target DNA and then targeted the CRISPR nuclease Cas9. Within these CRISPR RNAs, the guide sequence typically corresponds to phage sequences, forming the natural mechanism for CRISPR antiviral defense, yet can be simply replaced by a sequence of interest to retarget the Cas9 nuclease. More achievement gained at an unprecedented scale by introducing a battery of short guide RNAs rather than a library of large, bulky proteins to multiplexed targeting by Cas9. The high efficiency of Cas9 as a site-specific targeting nuclease, plus the possibility of highly multiplexed modifications make a high possibility for a broad range of biological applications across basic research to biotechnology and medicine.

The era of straightforward genome editing boosts ethical questions that will need to be addressed by scientists and society widely. How can we utilize this powerful tool in such a way as to assure maximum benefit while minimizing risks?(19) The identification of the CRISPR-Cas9 technology underscores the way in which many inventions having advanced molecular biology and medicine emerged, through basic research on natural mechanisms of DNA replication, repair, and defense against viruses. In many cases, key methodologies turned up from the study of bacteria. The CRISPR-Cas9 technology originated through a similar process, once the mechanism underlying how CRISPRCas9 system works was understood, it could be harnessed for applications in molecular biology and genetics that were not previously envisioned.(19) This review will give us the insight of how far this genome-editing technology which is applied as a new hope in treating currently "impossible" illness.

\section{CRISPR-Cas Immune System in Procaryotes}

It was conceived after a yogurt company in 2007 identified an unexpected defense mechanism that its bacteria use to fight off viruses. Then the birth announced in 2012 followed by rapid and crucial progress within a year. Now, it has matured into a molecular marvel, and much of the world, not just biologists, are taking notice of the genome-editing method CRISPR, Science's 2015 Breakthrough of the Year.(20) The battle for survival between bacteria and the viruses which infect them (phages) has led to the evolution of many bacterial defense systems and phage-encoded antagonists of these systems. CRISPR and the Cas genes comprise an adaptive immune system that is one of the most widespread means by which bacteria defend themselves against phages.(21-24)

CRISPR-Cas systems are classified into three major types, namely type I, type II and type III, and also into 12 subtypes, given their genetic content and structural and functional differences.(25,26) These types and subtypes core defining features based on the Cas genes and the proteins they encode. The immensely varies genetics and functions illustrate how diverse the biochemical functions they can carry throughout CRISPR-mediated immunity in each different steps. The RNA recognition motif is 
widely spread in many Cas proteins, and most of the Cas families of proteins carry functional domains which interact with nucleic acids, such as DNA binding, RNA binding, helicase and nuclease motifs.(25-29) Cas 1 and Cas 2 occurs genetically across types and subtypes, while Cas 3, 9 and 10 respectively designated as the signature genes for type I, II and III. Type II system phylogenetically has only been identified in bacteria, yet there is a bias for type I systems in bacteria and type III systems in archaea and hyperthermophiles.(30)

Adaptive immunity occurs in three stages [for recent reviews, (30-32)]. Those stages are: (i) insertion of a short sequence of the invading DNA into the CRISPR array as a spacer sequence; (ii) transcription of precursor CRISPR RNA (pre-crRNA) which goes through maturation to yield individual crRNAs, each composed of a repeat portion and an invader-targeting spacer portion; also (iii) crRNAdirected cleavage of foreign nucleic acid because of Cas proteins at sites complementary to crRNA spacer sequence (Figure 1). In this overall theme, three CRISPR-Cas system types (I, II and III) use distinct molecular mechanisms to achieve nucleic acid recognition and cleavage. $(22,25)$ The protospacer adjacent motif (PAM), or also known as a short sequence motif adjacent to the crRNA-targeted sequence on the invading DNA, has significant role in the stages of adaptation and interference in type I and type II systems.(33-36) The type I and type III systems use a large complex of Cas proteins for crRNA-guided targeting.(3742) However, the type II system requires merely a single protein for RNA-guided DNA recognition and cleavage, a property that proved to be highly useful for genome engineering applications. $(19,43,44)$
CRISPR systems are adaptable immune mechanisms used by many bacteria to protect themselves from foreign nucleic acids, such as viruses or plasmids.(30,45-47) Type II CRISPR systems incorporate sequences from invading DNA between CRISPR repeat sequences encoded as arrays in the bacterial host genome. Transcripts of the CRISPR repeat arrays are processed into crRNA, each harboring a variable sequence transcribed from the invading DNA, or known as the "protospacer" sequence, and part of the CRISPR repeat. Each crRNA hybridizes with a second RNA, which is known as the transactivating crRNA (tracrRNA) (48), and these two RNAs complex with the Cas9 nuclease (43). Only when PAMs located adjacent to the protospacer-encoded portion of the crRNA, Cas9 will be directed to cleave complementary target-DNA sequences. The type II CRISPR system from Streptococcus pyogenes has been adjusted for inducing sequence-specific DSBs and targeted genome editing.(43) In simple words, genome editing could be performed if the Cas 9 nuclease and a guide RNA, amount to a fusion of a crRNA and a fixed tracrRNA can be incorporated into and/or expressed in cells or an organism.(49)

Targeted genome editing using engineered nucleases has rapidly moved from being a niche technology to a mainstream method used by many biological researchers. This widespread adoption has been greatly fueled by the emergence of CRISPR technology, a new approach for generating RNA-guided nucleases, for example Cas9. Genome editing mediated by these nucleases has been used to quickly, easily and efficiently modify endogenous genes in a broad variety of biomedically relevant cell types and in organisms that have traditionally been challenging

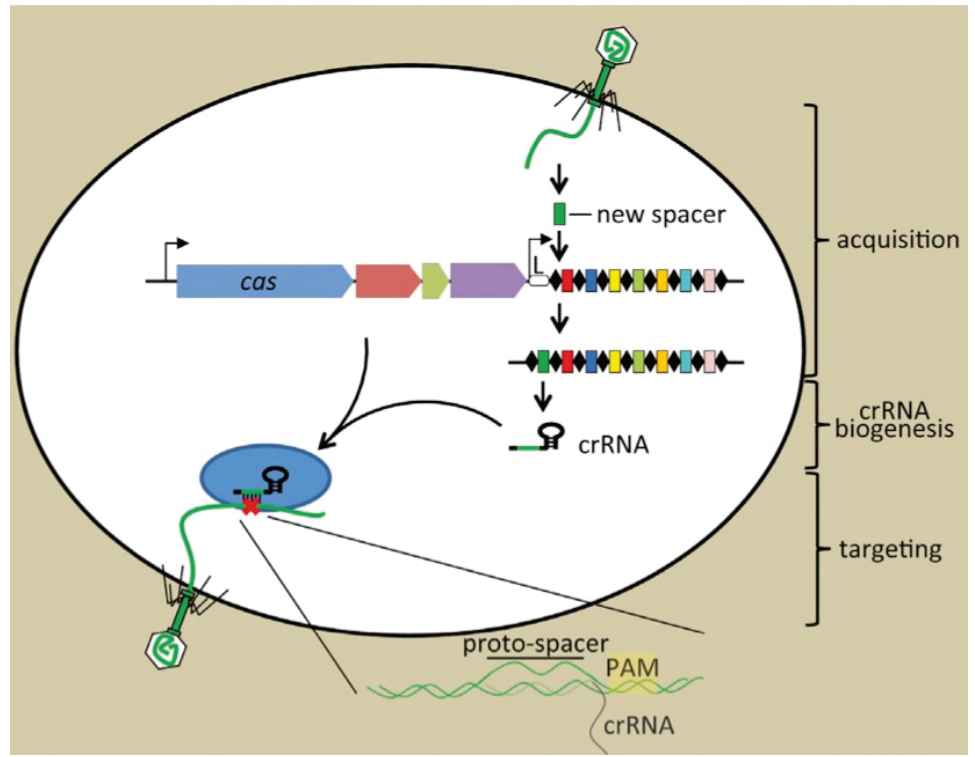

Figure 1. The Three Stages of CRISPR Immunity.(30) (Adapted with permission from Cell Press). 
to manipulate genetically. The potency of these systems to perform targeted, hugely efficient alterations of genome sequence and gene expression will certainly transform biological research and spur the development of novel molecular therapeutics for human disease.(49)

\section{Genome-Editing Technologies}

We need to understand the complex and dynamic functions of multiple genes network to able precisely manipulate genes, involving genes pathways which drive many essential cellular activities, including genome replication and repair, cell division and differentiation, also disease progression and inheritance.(50) The science of genetics relies heavily on the analysis of mutations and the phenotypes they cause. Many geneticists explore targetable nucleases to particular genes of interest which provide the ability for any direct mutations and precise sequence changes. This will continually create excitation to improve more new technologies.(51-53) The development of tools to generate DNA breaks, activate (54), repress or label genomic loci $(55,56)$ and remodel chromatin (57) in a controlled, targeted manner will hugely aid the studies of a broad range of biological issues, including gene and genomic functions. The ability to specifically modify the genome also holds significant promise for targeted gene therapies.(58)

Gene therapy has historically been defined as insertion of new genes into human cells. Current technologies in this field facilitate a new paradigm to achieve a therapeutic effect by precisely manipulating one or more sequences of the human genome, include correcting gene mutations that cause disease, adding genes to specific sites in the genome for therapeutic purpose, or removing destructive genes or genome sequences.(59) One way to explore the function of genes is to agitate their expression through repression. The dominant tool for programmed knockdown of mRNAs is RNA interference (RNAi).(60) Yet, RNAi has pervasive problems with off-target effects, which can be especially confounding in the context of large-scale screens.(61-63) RNAi is mediated by cytoplasmic argonaute proteins so that gene silencing could be performed by depletion of cytosolic mRNA targets.(64)

The discovery of using targeted DNA DSBs to stimulate the endogenous cellular repair machinery soon become the foundation to gene editing. Breaks in the DNA are typically repaired through one of two major pathways, which are homology-directed repair (HDR) or NHEJ.(65)
HDR depends on strand invasion of the broken end into a homologous sequence and subsequent repair of the break in a template-dependent manner.(66) Maria Jasin lab reported an original work about stimulating the efficiency of gene targeting through HR in mammalian cells via a DSB introducing at the target site. $(6,67,68)$ Alternatively, NHEJ functions to repair DSBs without a template through direct religation of the cleaved ends.(69) This repair pathway is error-prone and often leads to indels at breaking site. Stimulation of NHEJ by site-specific DSBs has been used to disrupt target genes in a huge variation of cell types and organisms by taking some benefit of these indels to alter the reading frame of a gene.(9,70-73) Armed with the capability to harness the cell's endogenous DNA repair machinery, it is now feasible to engineer a broad variety of genomic changes in a site-specific manner. $(59,74)$ The repairing process a DSB is shown by Figure 2 .

A concerted effort by various academic and industrial groups to develop programmable DNA recognition and cleavage technologies was inspired by the demonstration of a site-specific DSB could be utilized to attain gene interruption and gene targeting in otherwise refractory cells.

Over the last 15 years, this effort has yielded several designer endonuclease platforms, including meganucleases $(75,76)$, ZFNs $(77,78)$, TALENs $(79,80)$ and CRISPR $(19,81)$ (Figure 3). ZFNs consist of DNAbinding modules derived from natural transcription factors which are linked to the nuclease domain of the Type IIS restriction enzyme, FokI. $(18,19)$ To cut the DNA, two ZFN molecules are required in a single site target, then the nuclease domain will be dimerized. TALENs employ DNA-binding modules from bacterial TALEs linked

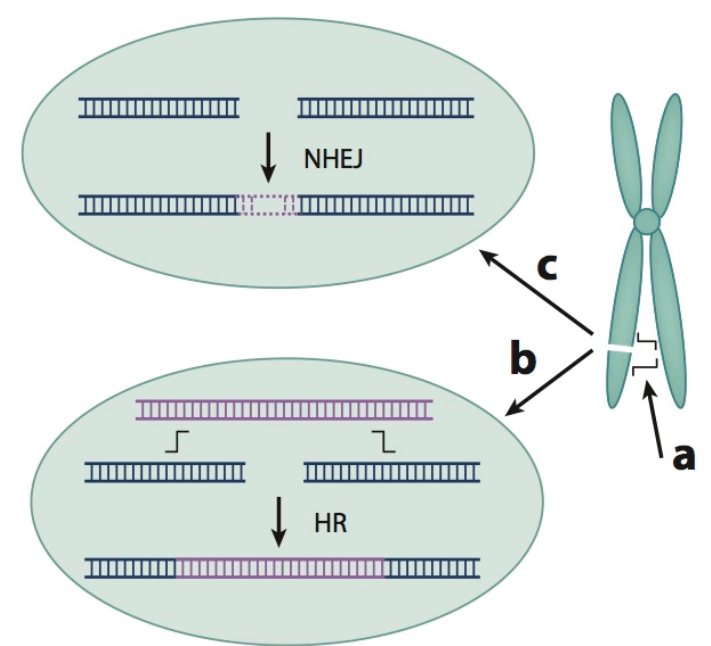

Figure 2. Repair of a DBS .(74) (Adapted with permission from Annual Reviews). 
to the same FokI cleavage domain.(20) The CRISPR/ Cas RNA-guided nucleases (RGNs) count on base-pairing between a guide RNA and the DNA target for recognition and on a multifunctional Cas9 protein for cleavage. $(21,22)$ We will discuss all of these types of reagents in detail after this. There are members of another class which have long recognition sites (15-30 bp) but do not have distinct binding and cleavage domains known as the homing endonucleases (HE) or meganucleases.(Figure4).

Once an endonuclease is designed to cut a given target sequence, it must be delivered to the therapeutically relevant cell. While there are few limitations on delivery to cultured cell lines, delivery to primary cells ex vivo (such as hematopoietic stem cells and T-cells) and in vivo delivery (such as to the liver) have many of the same limitations as other classical "gene therapy" approaches. It is the constraints on the immunogenicity and packaging capacity of the delivery modality.(81) Specificity of genome-editing reagents is paramount in therapeutics, as off-target mutations could lead to unintended side-effects. The inherent specificity of a given enzyme (independent of the target choice and its relative abundance of near-cognate matches in the genome) is dictated by both the DNAbinding specificity of enzyme and the catalytic mechanism employed to introduce the DNA break.(81)

A number of factors contribute to the absolute efficiency of a given gene-editing procedure, but most paramount is the quality of the nuclease. Considerations and observations for the overall editing rate, the number of edits that can be made simultaneously, and how editing outcome can potentially be influenced by the unique biochemistry of the different platforms. In addition to the quality and attributes of the nuclease, efficiency of editing can depend on several platform independent variables including the cell type (75), cell cycle (82), epigenetics at the target site $(83,84)$ and delivery kinetics.

We still facing some tricky challenges on the technological side, about how to guarantee off-target

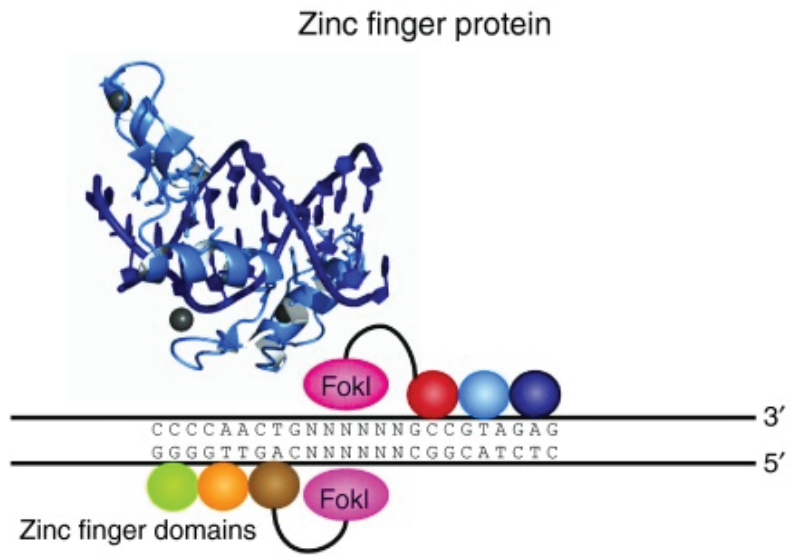

TALE

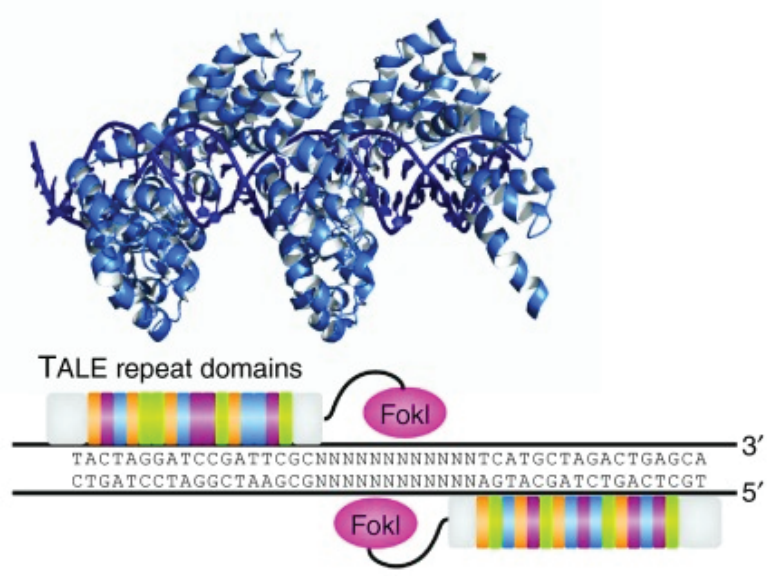

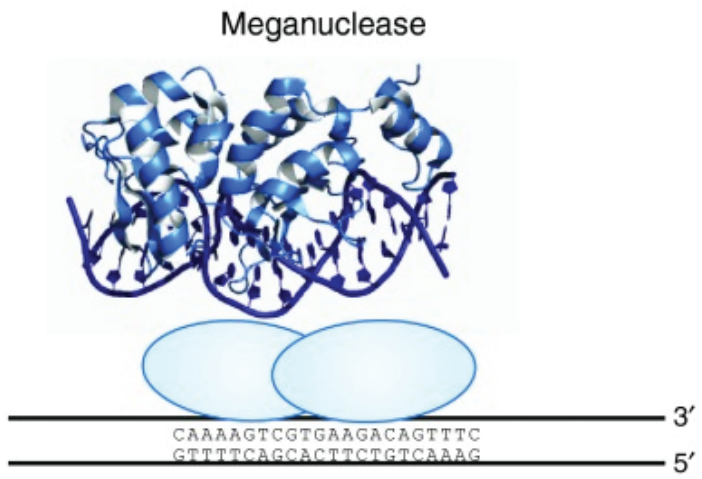

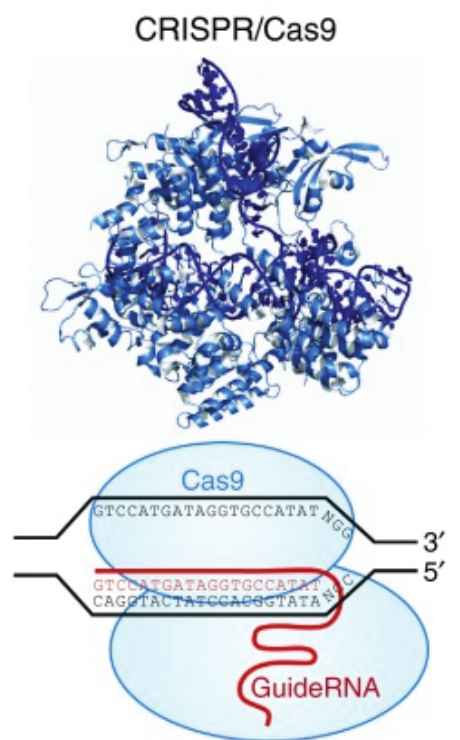

Figure 3. Common DNA targeting platforms for genome editing.(59) (Adapted with permission from American Society of Gene \& Cell Therapy). 

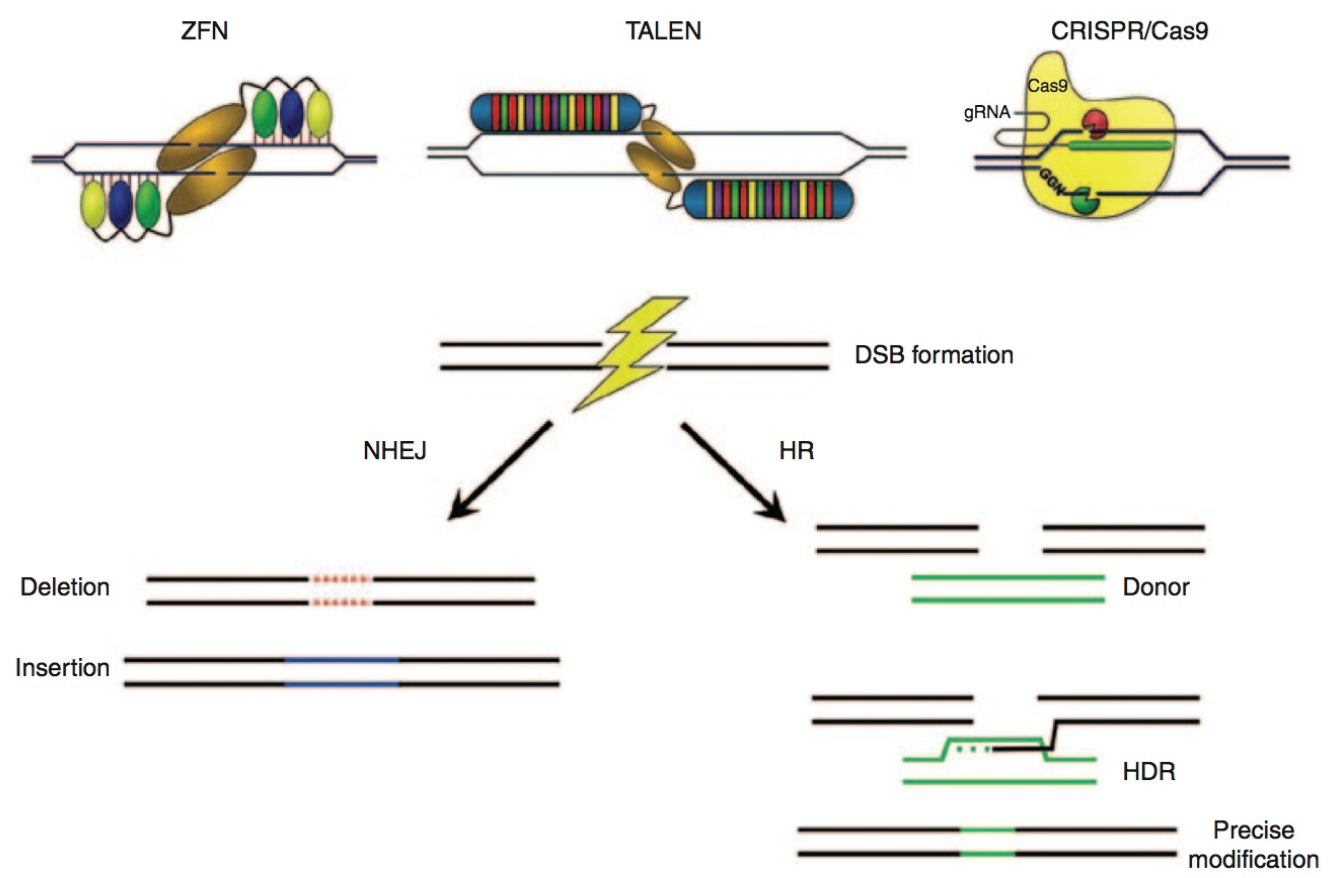

Figure 4. Classes of designer nucleases and gene-editing outcomes. Targeted DSB can be induced using ZFNs, TALENs, or CRISPR/ Cas9. DNA breaks are repaired via endogenous repair pathways such as NHEJ and HR.(58) (Adapted with permission from American Society of Gene \& Cell Therapy).

cleavage will not lead to mutations and compromise the expected benefits. Good progress is being made in both minimizing (85-88) and detecting (89) off-target effects, but the bar should be set very high before heritable modifications are pursued. We don't have decent control over the types of modifications produced at the genomic target. After CRISPR/Cas (or ZFN or TALEN) cleavage, cellular repair continues to introduce local mutations or copy sequences from a homologous donor DNA. The second process was more covetable for most therapeutic applications, but the former typically dominates and must be minimized. After directing most of the current research to solve this issue, no effective approach has yet arrived. Any effective alternatives in current practices, particularly pre-implantation screening should be pointed out, and on the clinical side we also need to identify conditions as reasonable candidates for germline treatment.(90) These alternatives have their own drawbacks, both practical and ethical. It seems possible that germline gene correction may ultimately be suggested as an alternative to such procedures, once technical standards have been met.(91)

Emerging gene-editing technologies are nearing a revolutionary phase in genetic medicine: accurately modifying or repairing causal genetic defects. Nowadays, these can carry out via programmable rare-cutting endonucleases, generate a targeted DNA breaks, involving any manipulation on DNA sequence, such as knocking out a deleterious gene, introducing a particular mutation, or directly repairing a deformed sequence by site-specific recombination, then engage and exploit endogenous DNA repair pathways to deliver site-specific genetic changes.(81)

\section{CRISPR-Cas 9: A Genome Engineering Tool}

Few discoveries transform a discipline overnight, but biologists these days can manipulate cells in ways impossible before, thanks to a peculiar form of prokaryotic adaptive immunity mediated by CRISPR. Many delicate studies performed and make clear how these immune systems function in bacteria and convince researchers about the technological potential of Cas9, an RNA-guided DNA cleaving enzyme, in genome engineering.(92) Precise genome engineering in live cells at any locus promises to facilitate basic research and to enable personalized medicine. In particular, the latest development of the CRISPR-Cas9 system into a versatile and easy-touse editing tool (43) has been celebrated as a scientific breakthrough in the field. As genome engineering is adapted to clinical applications, a high level of precision, especially the avoidance of editing at sites other than the intended target, will be indispensable.(93) 
The CRISPR-Cas system is widely found in bacterial and archaeal genomes as a defense mechanism against invading viruses and plasmids.(30,47,94-97) To target DNA, the type II CRISPR-Cas system from Streptococcus pyogenes depend on one protein, which is the nuclease Cas9, and two noncoding RNAs, namely crRNA and tracrRNA, which further can be fused into one single guide RNA (sgRNA). The Cas9/sgRNA complex binds doublestranded DNA sequences which consist of a sequence match to the first 17-20 nucleotides of the sgRNA if the target sequence is followed by a PAM (Figure 5). After the two independent nuclease domains in Cas9 bound, they will each cleave one of the DNA strands three bases upstream of the PAM, and leaving a blunt end DNA DSB. DSBs can be repaired mainly through either NHEJ pathway or HDR. NHEJ typically leads to short indels near the cutting site, whilst HDR can be used to introduce specific sequences into the cutting site, if exogenous template DNA is available. This finding bricked the way of the Cas9 application as a genome-engineering tool in other species. In this review, we only focus on target specificity of the CRISPR-Cas9 system, so for further discussion, we refer readers to other excellent articles as follows: $(1,98-100)$.

Following the 2012 publication of Jinek, et al., three studies in January 2013 illustrated that CRISPR-Cas9 represents an efficient tool to refine the genomes of human cells. $(17,18,43,101)$ The "humanized" versions of Streptococcus pyogenes Cas9 $(17,18,101)$ and Streptococcus thermophilus Cas9 (17) were coexpressed with customdesigned sgRNAs $(17,18,101)$ or with tracrRNA coexpressed with custom-designed crRNAs in human embryonic kidney,

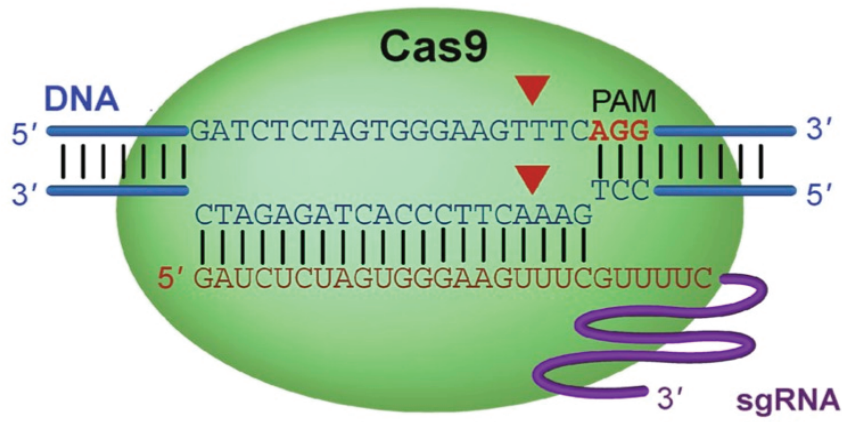

Figure 5. The CRISPR-Cas9 system. The sgRNA (purple) targets the Cas9 protein to genomic sites containing sequences complementary to the $5^{\prime}$ end of the sgRNA. The target DNA sequence needs to be followed by a PAM.(100) (Adapted with permission from Higher Education Press and Springer-Verlag Berlin Heidelberg). chronic myelogenous leukemia, or induced pluripotent stem cells (iPSC) $(17,18,101)$, as well as in mouse cells (17). The expected alterations in the target DNA were detected, indicating that site-specific DSBs by RNA-guided Cas9 had stimulated gene editing by non-homologous end joining repair or gene replacement by HDR. Targeting with multiple sgRNAs, also referred to as multiplexing, was successfully achieved.(17,18) RNA-programmable Streptococcus pyogenes Cas9-mediated editing has now been applied to various human cells and embryonic stem cells.(1,49,98,102-105). Although direct comparisons can be inconvenient to assess because of differences in target sites and protein expression levels, some analyses display that CRISPR-Cas9-mediated editing efficiencies can reach $80 \%$ or more depending on the target, which is as high as or higher than the levels observed using ZFNs or TALENs. $(104,106)$

Detailed characterization of the Cas9-guide complex and its interference mechanism in the past $(38,107)$ has led to a revolution of CRISPR-based genetic engineering $(108,109)$. The revolution includes directed recombination in bacteria $(110,111)$, transcriptional activation and repression of synthetic regulons $(112,113)$ and genome editing in eukaryotic cells, ranging from yeast to plant and from zebrafish to human (114). In addition for the directed silencing of the gene expression alternative system, we may also use RNA targeting by type III-B systems, as well as by Cas9. In terms of applications of CRISPR-associated nucleases in general, and Cas9 in particular, the sky seems to be the limit. Many improvements could be endeavor such as lowering the stringency of its PAM dependence and reducing its off-target cleavage. It's crucial to also improve our understanding of the fundamental details of CRISPRCas structure and function to optimize further expansion of CRISPR-Cas system applicability.(115)

The significant advantages of the CRISPR/Cas system versus ZFNs and TALENs are as follows: (1) a single protein is required, and it is always the same, no protein engineering is needed; (2) targeting depends on base pairing, so sgRNA design requires only knowledge of the WatsonCrick rules; (3) new sgRNAs are very easily produced, (4) because of advantages 1-3, it is feasible to attack multiple targets simultaneously with mixed sgRNAs.(74)

The epigenome is a layer of regulatory information superimposed on the genome. It's involved in the positions, compositions, and modifications of nucleosomes as well as modifications of DNA bases.(116) The epigenetics 
community has done a major ongoing effort that has already yielded millions of putative regulatory elements to map the epigenomic components genome-wide in many cell types. Recent reports in Nature Biotechnology by Hilton, et al., and in Nature Methods by Kearns, et al., have now addressed this need with an epigenome editing technology based on CRISPR-Cas9.(116-118) The studies that combining CRISPR-Cas9 ability in directing effectors to specific genomic sites with well-characterized, histonemodifying domains functionally characterized the chromatin states of specific genomic elements and show the robust, specific transcriptional outcomes of histone modifications modulation.(119) The outcome of those studies suggest that using CRISPR-Cas9 for targeted epigenome editing was very promising to be a simple but powerful method for probing the effects of histone modifications at specific loci.

\section{CRISPR-Cas 9 Applications}

The Human Genome Project has earned a fairly complete catalog of cellular components, and a major goal is moving forward will be to classify all genetic elements involved in normal biological processes and disease.(120) With advances in gene editing enabled by the CRISPR-Cas system $(17,18,43,121)$, it is no longer quixotic to seek a comprehensive picture of cellular circuitry for human cells (122).

Journeyed from dreams about treating inherited disorders, gene therapy now encircled a wide range of strategies, started from the assumption that monogenic diseases would be the easiest to target. Classically, this therapy focused on enhancing endogenous DNA gene expression. These approaches rely on variety of viral vectors to transfer functional genes, adjusted to the virus intrinsic ability to effectively transduce in human cells.

Thus, gene editing grows further on a thought about utilizing targeted disruption, insertion, excision and correction in both ex vivo and in vivo settings to permanently modify a genomic sequence of interest. Yet we foresee these advances to revolutionize larger without ignoring the safety concerns, modification efficacy and gene-editing tools to target cell types.(123) CRISPR-Cas9 nuclease system raises the hopes for a robust and precise modifying genomic sequences, make it possible to study of gene function at nucleotide resolution. To find a permanent way of correcting genetic mutation will rise an important advance in future therapy.(50)
In the year of 2012, Cas9, programmed initial demonstration to cut various DNA sites in vitro, was published in a flurry of papers in the next year, suggested that this platform could efficiently function in various cells and organisms.(43) Initial proof-of-principle studies displayed that Cas9 could be targeted to endogenous genes in bacteria (110), cultured altered human cancer cell lines and human pluripotent stem cells in culture $(17,18,101,121)$, also in a whole organism, the zebrafish (106). Subsequently, Cas9 has been used to refine genes in yeast (124), tobacco $(125,126)$, thale cress $(127)$, rice $(127,128)$, wheat $(127)$, sorghum (129), mice $(130,131)$, rats (132), rabbits (133), frogs (134), fruit flies $(135,136)$, silkworms (137) and roundworms (138).

Here we highlight a few examples that illustrate the power of the technology. The first instance is the precise reproduction of tumor-associated chromosomal translocations that come about during carcinogenesis through an illegitimate non-homologous joining of two chromosomes. The ability of CRISPR-Cas9 to introduce DSBs at defined positions has made it possible to generate human cell lines and primary cells bearing chromosomal translations resembling those described in cancers such as lung cancer (137), acute myeloid leukemia, and Ewing's sarcoma $(138,139)$ (Figure 6). An improved method to generate liver cancer or myeloid malignancy models in mice facilitated by CRISPR-Cas9 was recently reported $(140,141)$. CRISPR-Cas9 thus provides a robust technology for studying genomic rearrangements and the development and progression of cancers or other diseases.(19)

Cas9 has already been widely used as a research tool, but the research expanded excitingly to develop Cas9 as a therapeutic technology for treating genetic disorders. Monogenic recessive disorder due to loss-of-function mutations (such as cystic fibrosis, sickle-cell anemia, or Duchenne muscular dystrophy) will be a prospect case to be corrected causatively by Cas9. This has numbers of advantages over traditional methods of gene augmentation which transfer functional genetic copies trough viral vector-mediated overexpression-particularly that the newly functional gene is expressed in its natural context. For disorders with haplosufficient affected genes (such as transthyretin-related hereditary amyloidosis or dominant forms of retinitis pigmentosum), Therapeutic benefit possibly achieved by using NHEJ to inactivate the mutated allele.

In addition to repairing mutations underlying inherited disorders, Cas9-mediated genome editing could also use to combat non-genetic or complex diseases by acquaint 


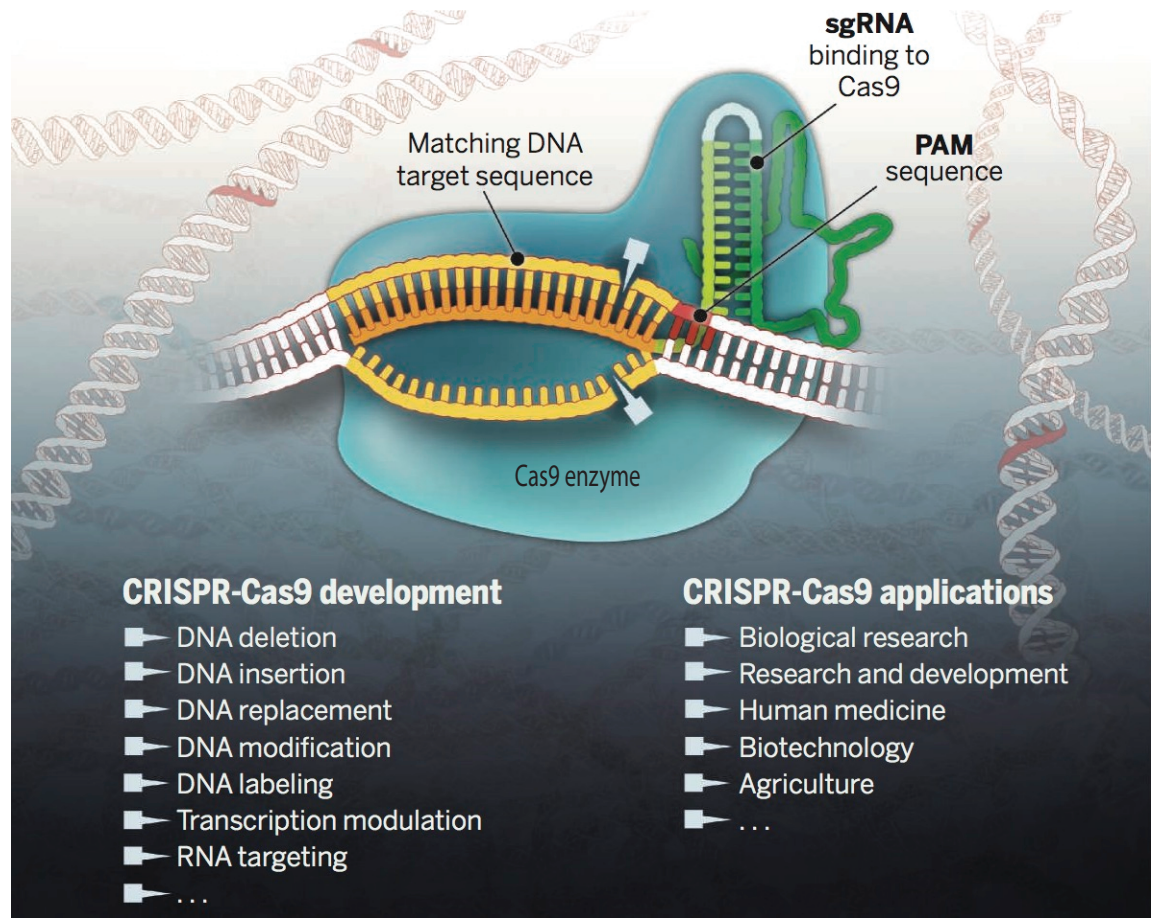

Figure 6. The Cas9 enzyme generates breaks in double-stranded DNA by using its two catalytic centers (blades) to cleave each strand of a DNA target site (yellow) beside a PAM sequence (red) and matching the 20-nucleotide sequence (orange) of the sgRNA).(19) (Adapted with permission from American Association for the Advancement of Science). protective mutations in somatic tissues. For example, NHEJ-mediated inactivation of the $\mathrm{C}-\mathrm{C}$ chemokine receptor type 5 (CCR5) in lymphocytes (142) may be a feasible strategy for circumventing HIV infection, while deletion of protein convertase subtilisin/kexin type 9 (PCSK9) (143) or angiopoietin (144) may provide therapeutic effects against statin-resistant hypercholesterolemia or hyperlipidemia. The unique advantage of this method rather than using sgRNAmediated protein knockdown is the ability to achieve permanent therapeutic benefit in one-time treatment. Of course every gene therapies proposed therapeutic use must count the favorable benefit-risk ratio.(1)

The ability to manipulate any genomic sequence by gene editing has created diverse opportunities to treating many different diseases and disorders (Figure 7). We will discuss the major categories of disease indications that have been pursued in preclinical models, as well as highlight the ongoing or planned clinical trials using gene-editing strategies. Gene editing applied most straightforward ex vivo in gene knocking out for autologous cell therapy using the relatively efficient NHEJ mechanism, where somatic cells can be isolated, modified and delivered back to the patient. By this method, viral infection or replication can be prevented. Hence, the most advanced gene-editing strategy to date is the ex vivo modification of T-cells to knock out the CCR5 co-receptor used for primary HIV infection. The initiative study showed that in mice engrafted with T-cells in which the CCR5 gene had been knocked out by ZFNs, the viral loads decreased and cluster of differentiation (CD) $4^{+}$ T-cell counts increased.(145)

Beyond addressing HIV infection, all of the geneediting platforms have also been applied to various other viral pathogens (146), including hepatitis B virus (147-154), herpes simplex virus (155-157), and human papillomavirus (158). Viral genomes will be removed by degradation following nuclease cleavage and by targeting crucial genes needed for genome stability, maintenance, and replication.

Cancer immunotherapy has been largely recognized as one of the biggest advances in biomedical research in recent years.(159) In particular, adoptive T-cell immunotherapy, in which autologous T-cells are designed to attack cancer antigens ex vivo and transferred back to the patient, has been impressively successful at treating some cases of lymphoma, leukemia, and melanoma.(160) Undeterred with those successes and promising ongoing clinical trial, gene editing could even more improve the potency of T-cell immunotherapy, as showed by many studies focused on knocking out the endogenous T-cell receptors with engineered nucleases.(161-164)

Similarly, the successful of $\mathrm{CD}^{+} 4^{+}$hematopoietic stem cell (HSC) gene editing and human pluripotent cells capable of differentiating into erythroid progenitors has opened new options for treating other hematologic disorders, including treating specific E6V point mutation in the $\beta$-globin gene account for sickle cell disease, and other types of mutations to $\beta$-globin as the cause of $\beta$-thalassemia. 


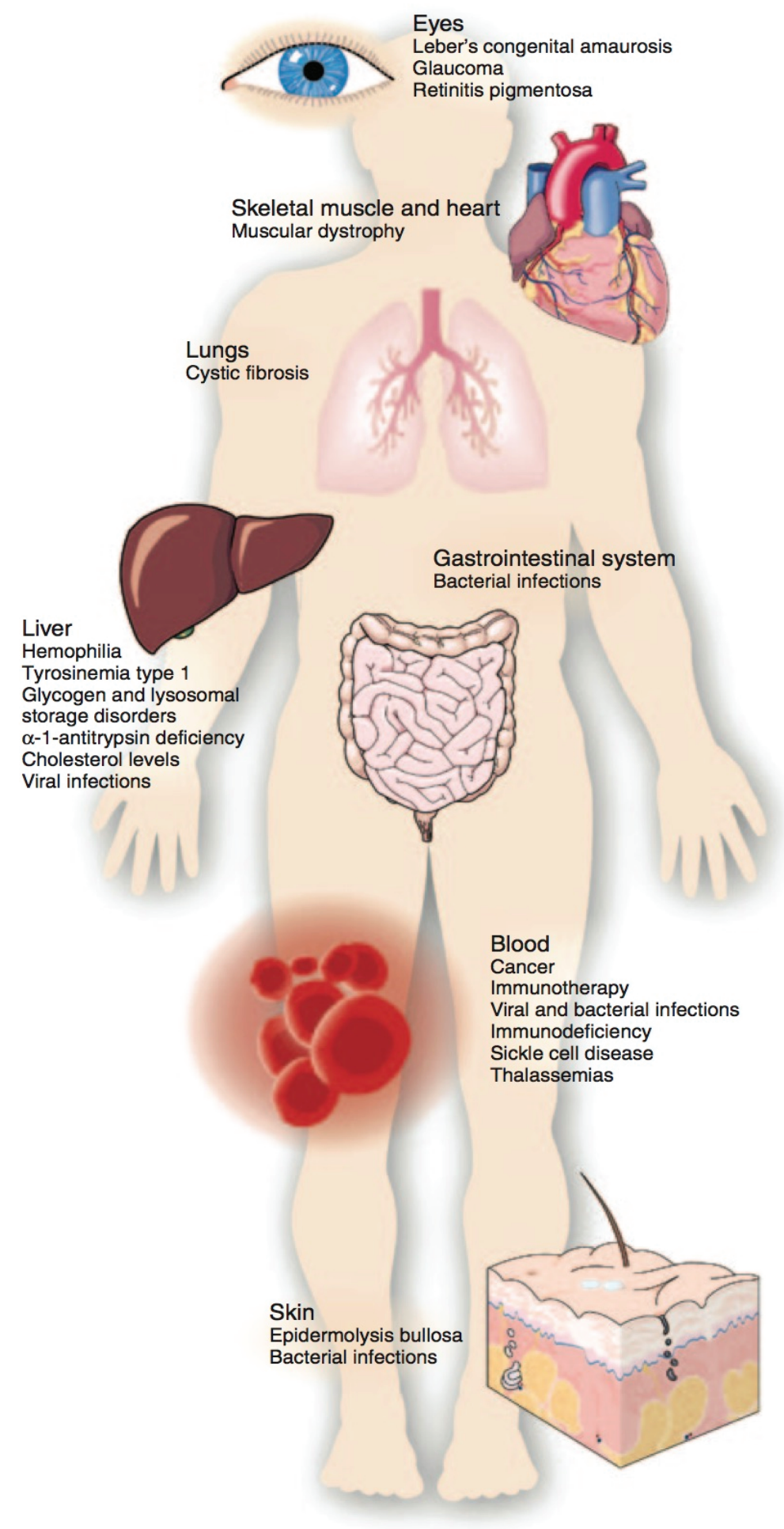

Figure 7. Diversity of targets for therapeutic genome editing.(59) (Adapted with permission from American Society of Gene \& Cell Therapy).

These globin mutations have been corrected by gene editing both in human iPSC that can be differentiated into functional erythrocytes (164-167) and directly in CD34+ HSCs.(168) Similar approaches have been developed for targeted integration of therapeutic transgenes into safe harbor sites in human iPSCs for $\alpha$-thalassemia (169) and Fanconi anemia (170).
In applications to the human therapy, we need to make sure that the treatment will cure the one intentionally addressed without causing another unexpected condition. Auspiciously that we are able to direct subtle changes to the endogenous target, so dangers inherent in earlier methods for delivery of therapeutic genes could be avoided.(171) 


\section{Ethical Implications of Human Germline Genome Editing}

In human and non-human modifying, genome engineering technology didn't offer lateral potencies. While in humans this technology preferred directed for curing a genetic disease, in other organisms, it present methods to reshape the biosphere for the advantage of the environment and human societies. However, we still do not know the unknown risks to human health and well-being yet.(172)

The CRIPSR-Cas9 system is quite simple that allows any researcher with knowledge of biology molecular to modify genome, and conduct a previously difficult or impossible study as feasible. For example, a study on CRISPR-Cas9 to correct genetic defects in whole animals by an introduction of DNA sequence, such as replacing a mutated gene underlying liver-based metabolic disease in a mouse model.(173) The technique also enables DNA sequence changes in pluripotent embryonic stem cells (18) which can then be cultured to produce specific tissues, such as cardiomyocytes or neurons (174). Those basic researches will lay a frame of the foundation for real strategies to cure human disease. The ability of CRISPR-Cas9 to precisely replicate the genetic basis for human diseases in model organisms can be utilized to lead an unprecedented insight into previously enigmatic disorders.

CRISPR-Cas9 technology, as well as other genome engineering methods, can be used to alter the DNA in the nuclei of reproductive cells which transmit information from one generation to the next (an organism's "germline"). Thus, it is now possible to carry out genome modification in fertilized animal eggs or embryos, thereby shifting the genetic makeup of every differentiated cell in an organism and so ensuring that the alterations will be passed on to the organism's progeny. It was also not impossible to apply this simple and widely available to set changes in human germline.(172)

Early this year, about a month after the National Academy of Sciences (NAS) International Summit on Human Gene Editing, Stafford Academy for Technology (STAT) and the Harvard School of Public Health conducted a poll of adults in the US on gene editing. Their main finding was that an overwhelming majority of Americans (83\%) believe it should be illegal to use gene editing to "improve the intelligence or physical characteristics" of unborn babies. The summit stated a consensus, not a new law but did conclude that it would be "irresponsible to proceed (with germline genetic manipulations) without resolution of safety issues and broad social consensus on application."(175)

Although it was very possible to bring CRISPR-Cas-9 to modify human germline, we have to consider that patient safety is paramount among the arguments against modifying the human germline (egg and sperm cells), because we can never be assured if the mosaic embryo created, its germline may carry the genetic alteration or not. Philosophically or ethically justifiable applications for this technology are moot until it becomes possible to prove safe outcomes and gain reproducible data over multiple generations. Due to safety and serious ethical reasons, around 40 countries until today, discourage or even ban germline modifications in human. Some countries indeed prohibited it a decade before the technical feasibility was confirmed in rats in the year 2009.(71,90)

\section{Conclusion}

The story of how a mysterious prokaryotic viral defense system turn into one of the most powerful and versatile platforms for engineering biology irradiate the importance of basic science research. Just as recombinant DNA technology benefited from the basic investigation of the restriction enzymes which are central to warfare between phage and bacteria, the latest generation of Cas9-based genome engineering tools are also based on components from the microbial antiphage defense system. It is likely that the future solutions for efficient and precise gene modification will be found in as of yet unexplored corners of the rich biological diversity of nature.

At last, by understanding the current studies of CRISPR application in creating tissue-based treatments for cancer and other currently untreatable diseases, every scientists' dream about genetic manipulation is getting closer. Charpentier described its capabilities as "mindblowing." For better or worse, the simple truth is, we all now live in CRISPR's world, and what next this method will grow, the sky is the limit.

\section{References}

1. Hsu PD, Lander ES, Zhang F. Development and applications of CRISPR-Cas9 for genome engineering. Cell. 2014; 157: 1262-78.

2. Capecchi MR. Altering the genome by homologous recombination. Science. 1989; 244: 1288-92. 
3. Rudin N, Sugarman E, Haber JE. Genetic and physical analysis of double-strand break repair and recombination in Saccharomyces cerevisiae. Genetics. 1989; 122: 519-34.

4. Plessis A, Perrin A, Haber JE, Dujon B. Site-specific recombination determined by I-SceI, a mitochondrial group I intron-encoded endonuclease expressed in the yeast nucleus. Genetics. 1992; 130: 451-60.

5. Rouet P, Smih F, Jasin M. Introduction of double-strand breaks into the genome of mouse cells by expression of a rare-cutting endonuclease. Mol Cell Biol. 1994; 14: 8096-106.

6. Choulika A, Perrin A, Dujon B, Nicolas JF. Induction of homologous recombination in mammalian chromosomes by using the I-SceI system of Saccharomyces cerevisiae. Mol Cell Biol. 1995; 15, 1968-73.

7. Bibikova M, Carroll D, Segal DJ, Trautman JK, Smith J, Kim YG, et al. Stimulation of homologous recombination through targeted cleavage by chimeric nucleases. Mol Cell Biol. 2001; 21: 289-97.

8. Bibikova M, Beumer K, Trautman JK, Carroll D. Enhancing gene targeting with designed zinc finger nucleases. Science. 2003; 300: 764. doi: $10.1126 /$ science. 1079512 .

9. Bibikova M, Golic M, Golic KG, Carroll D. Targeted chromosomal cleavage and mutagenesis in Drosophila using zinc-finger nucleases. Genetics. 2002; 161: 1169-75.

10. Smith J, Grizot S, Arnould S, Duclert A, Epinat JC, Chames P, et al. A combinatorial approach to create artificial homing endonucleases cleaving chosen sequences. Nucleic Acids Res. 2006; 34: e149. doi: 10.1093/nar/gk1720.

11. Urnov FD, Miller JC, Lee YL, Beausejour CM, Rock JM, Augustus $\mathrm{S}$, et al. Highly efficient endogenous human gene correction using designed zinc-finger nucleases. Nature. 2005; 435: 646-51.

12. Miller JC, Holmes MC, Wang J, Guschin DY, Lee YL, Rupniewski I, et al. An improved zinc-finger nuclease architecture for highly specific genome editing. Nat Biotechnol. 2007; 25: 778-85.

13. Christian M, Cermak T, Doyle EL, Schmidt C, Zhang F, Hummel A, et al. Targeting DNA double-strand breaks with TAL effector nucleases. Genetics. 2010; 186: 757-61.

14. Miller JC, Tan S, Qiao G, Barlow KA, Wang J, Xia DF, et al. A TALE nuclease architecture for efficient genome editing. Nat Biotechnol. 2011; 29: 143-8.

15. Boch J, Scholze H, Schornack S, Landgraf A, Hahn S, Kay S, et al. Breaking the code of DNA binding specificity of TAL-type III effectors. Science. 2009; 326: 1509-12.

16. Moscou MJ, Bogdanove AJ. A simple cipher governs DNA recognition by TAL effectors. Science. 2009; 326: 1501. doi: 10.1126/science.1178817.

17. Cong L, Ran FA, Cox D, Lin S, Barretto R, Habib N, et al. Multiplex genome engineering using CRISPR/Cas systems. Science. 2013; 339: 819-23.

18. Mali P, Yang L, Esvelt KM, Aach J, Guell M, DiCarlo JE, et al. RNAguided human genome engineering via Cas9. Science. 2013; 339: 823-6.

19. Doudna JA, Charpentier E. The new frontier of genome engineering with CRISPR-Cas9. Science. 2014; 346: 1077-87.

20. Travis J. Making the cut: CRISPR genome-editing technology shows its power. Science. 2015; 350: 1456-7.

21. Barrangou R, Fremaux C, Deveau H, Richards M, Boyaval P, Moineau $\mathrm{S}$, et al. CRISPR provides acquired resistance against viruses in prokaryotes. Science. 2007; 315: 1709-12.

22. Makarova KS, Haft DH, Barrangou R, Brouns SJ, Charpentier E, Horvath $\mathrm{P}$, et al. Evolution and classification of the CRISPR-Cas systems. Nature Rev Microbiol. 2011; 9: 467-77.
23. Jore MM, Brouns SJ, van der Oost, J. RNA in defense: CRISPRs protect prokaryotes against mobile genetic elements. Cold Spring Harb Perspect Biol. 2012; 4: a003657. doi: 10.1101/cshperspect. a003657.

24. Bondy-Denomy J, Garcia B, Strum S, Du M, Rollins MF, HidalgoReyes Y, et al. Multiple mechanisms for CRISPR-Cas inhibition by anti-CRISPR proteins. Nature. 2015; 526: 136-9.

25. Makarova KS, Aravind L, Wolf YI, Koonin EV. Unification of Cas protein families and a simple scenario for the origin and evolution of CRISPR-Cas systems. Biol Direct. 2011; 6: 38. doi: 10.1186/17456150-6-38.

26. Makarova KS, Wolf YI, Koonin EV. The basic building blocks and evolution of CRISPR-cas systems. Biochem Soc Trans. 2013; 41: 1392-400.

27. Makarova KS, Aravind L, Grishin NV, Rogozin IB, Koonin EV. A DNA repair system specific for thermophilic Archaea and bacteria predicted by genomic context analysis. Nucleic Acids Res. 2002; 30: 482-96.

28. Makarova KS, Grishin NV, Shabalina SA, Wolf YI, Koonin EV. A putative RNA-interference-based immune system in prokaryotes: computational analysis of the predicted enzymatic machinery, functional analogies with eukaryotic RNAi, and hypothetical mechanisms of action. Biol. Direct. 2006; 1: 7. doi: 10.1186/17456150-1-7.

29. Makarova KS, Haft DH, Barrangou R, Brouns SJ, Charpentier E, Horvath P, et al. Evolution and classification of the CRISPR-Cas systems. Nat Rev Microbiol. 2011; 9: 467-77.

30. Barrangou R, Marraffini LA. CRISPR-Cas systems: prokaryotes upgrade to adaptive immunity. Mol Cell. 2014; 54: 234-44.

31. van der Oost J, Westra ER, Jackson RN, Wiedenheft B. Unravelling the structural and mechanistic basis of CRISPR-Cas systems. Nat Rev Microbiol. 2014; 12: 479-92.

32. Bondy-Denomy J, Davidson AR. To acquire or resist: The complex biological effects of CRISPR-Cas systems. Trends Microbiol. 2014; 22: $218-25$.

33. Mojica JM, Díez-Villaseñor C, García-Martínez J, Soria E. Intervening sequences of regularly spaced prokaryotic repeats derive from foreign genetic elements. J Mol Evol. 2005; 60: $174-82$.

34. Deveau H, Barrangou R, Garneau JE, Labonté J, Fremaux C, Boyaval $\mathrm{P}$, et al. Phage response to CRISPR-encoded resistance in Streptococcus thermophilus. J Bacteriol. 2008; 190: 1390-400.

35. Horvath P, Romero DA, Coûté-Monvoisin AC, Richards M, Deveau $\mathrm{H}$, Moineau S, et al. Diversity, activity, and evolution of CRISPR loci in Streptococcus thermophilus. J Bacteriol. 2008; 190: 140112.

36. Shah SA, Erdmann S, Mojica FJM, Garrett RA. Protospacer recognition motifs: mixed identities and functional diversity. RNA Biol. 2013; 10: 891-9.

37. Brouns SJ, Jore MM, Lundgren M, Westra ER, Slijkhuis RJ, Snijders AP, et al. Small CRISPR RNAs guide antiviral defense in prokaryotes. Science. 2008; 321: 960-4.

38. Nam KH, Haitjema C, Liu X, Ding F, Wang H, DeLisa MP, et al. Cas5d protein processes pre-crRNA and assembles into a cascadelike interference complex in subtype I-C/Dvulg CRISPR-Cas system. Structure. 2012; 20: 1574-84.

39. Haurwitz RE, Jinek M, Wiedenheft B, Zhou K, Doudna JA. Sequenceand structure-specific RNA processing by a CRISPR endonuclease. Science. 2010; 329: 1355-8.

40. Hatoum-Aslan A, Maniv I, Marraffini LA. Mature clustered, regularly interspaced, short palindromic repeats RNA (crRNA) 
length is measured by a ruler mechanism anchored at the precursor processing site. Proc Natl Acad Sci USA. 2011; 108: 21218-22.

41. Rouillon C, Zhou M, Zhang J, Politis A, Beilsten-Edmands V, Cannone G, et al. Structure of the CRISPR interference complex CSM reveals key similarities with cascade. Mol Cell. 2013; 52: 124-34.

42. Hale CR, Zhao P, Olson S, Duff MO, Graveley BR, Wells L, et al. RNA-guided RNA cleavage by a CRISPR RNA-Cas protein complex. Cell. 2009; 139: 945-56.

43. Jinek M, Chylinski K, Fonfara I, Hauer M, Doudna JA, Charpentier E. A programmable dual-RNA-guided DNA endonuclease in adaptive bacterial immunity. Science. 2012; 337: 816-21.

44. Gasiunas G, Barrangou R, Horvath P, Siksnys V. Cas9-crRNA ribonucleoprotein complex mediates specific DNA cleavage for adaptive immunity in bacteria. Proc Natl Acad Sci USA. 2012; 109: E2579-86

45. Wiedenheft B, Sternberg SH, Doudna JA. RNA-guided genetic silencing systems in bacteria and archaea. Nature. 2012; 482: 331-8.

46. Fineran PC, Charpentier E. Memory of viral infections by CRISPRCas adaptive immune systems: acquisition of new information. Virology. 2012; 434: 202-9.

47. Horvath P, Barrangou R. CRISPR/Cas, the immune system of bacteria and archaea. Science. 2010; 327: 167-70.

48. Deltcheva E, Chylinski K, Sharma CM, Gonzales K, Chao Y, Pirzada ZA, et al. CRISPR RNA maturation by trans-encoded small RNA and host factor RNase III. Nature. 2011; 471: 602-7.

49. Sander JD, Joug JK. CriSPr-Cas systems for editing, regulating and targeting genomes. Nat Biotechnol. 2014; 32: 347-55.

50. Dominiguez AA, Lim WA, Qi LS. Beyond editing: repurposing CRISPR-Cas9 for precision genome regulation and interrogation. Nat Rev Mol Cell Biol. 2016; 17: 5-15.

51. Segal DJ, Meckler JF. Genome engineering at the dawn of the golden age. Annu Rev Genomics Hum Genet. 2013; 14: 135-58

52. Cai M, Yang Y. Targeted genome editing tools for disease modeling and gene therapy. Curr Gene Ther. 2014; 14: 2-9.

53. Cox DB, Platt RJ, Zhang F. Therapeutic genome editing: prospects and challenges. Nat Med. 2015; 21: 121-31.

54. Wilber A, Tschulena U, Hargrove PW, Kim YS, Persons DA, Barbas $\mathrm{CF}$ 3rd, et al. A zinc-finger transcriptional activator designed to interact with the gamma-globin gene promoters enhances fetal hemoglobin production in primary human adult erythroblasts. Blood. 2010; 115: 3033-41.

55. Cong L, Zhou R, Kuo YC, Cunniff M, Zhang F. Comprehensive interrogation of natural TALE DNA-binding modules and transcriptional repressor domains. Nat Commun. 2012; 3: 968. doi: 10.1038/ncomms1962.

56. Ma H, Naseri A, Reyes-Gutierrez P, Wolfe SA, Zhang S, Pederson T. Multicolor CRISPR labeling of chromosomal loci in human cells. Proc Natl Acad Sci USA. 2015; 112: 3002-7.

57. Hilton IB, D'Ippolito AM, Vockley CM, Thakore PI, Crawford GE, Reddy TE, et al. Epigenome editing by a CRISPR-Cas9-based acetyltransferase activates genes from promoters and enhancers. Nat Biotechnol. 2015; 33: 510-7.

58. Lee CM, Cradick TJ, Fine EJ, Bao G. Nuclease target site selection for maximizing on-target activity and minimizing off-target effects in genome editing. Mol Ther. 2016; 24: 475-87.

59. Maeder ML, Gersbach CA. Genome-editing technologies for gene and cell therapy. Mol Ther. 2016; 24: 430-46.

60. Chang K, Elledge SJ, Hannon GJ. Lessons from Nature: microRNAbased shRNA libraries. Nat Methods. 2006; 3: 707-14.
61. Adamson B, Smogorzewska A, Sigoillot FD, King RW, Elledge SJ. A genome-wide homologous recombination screen identifies the RNA-binding protein RBMX as a component of the DNA-damage response. Nat Cell Biol. 2012; 14: 318-28.

62. Jackson AL, Bartz SR, Schelter J, Kobayashi SV, Burchard J, Mao $\mathrm{M}$, et al. Expression profiling reveals off-target gene regulation by RNAi. Nat Biotechnol. 2003; 21: 635-7.

63. Sigoillot FD, Lyman S, Huckins JF, Adamson B, Chung E, Quattrochi B, et al. A bioinformatics method identifies prominent off-targeted transcripts in RNAi screens. Nat Methods. 2012; 9: 363-6.

64. Gilbert LA, Horlback MA, Adamson B, Villalta JE, Chen Y, Whitehead EH, et al. Genome-scale CRISPR-mediated control of gene repression and activation. Cell. 2014; 159: 647-61.

65. Takata M, Sasaki MS, Sonoda E, Morrison C, Hashimoto M, Utsumi $\mathrm{H}$, et al. Homologous recombination and non-homologous end-joining pathways of DNA double-strand break repair have overlapping roles in the maintenance of chromosomal integrity in vertebrate cells. EMBO J. 1998; 17: 5497-508.

66. Szostak JW, Orr-Weaver TL, Rothstein RJ, Stahl FW. The doublestrand- break repair model for recombination. Cell. 1983; 33: 25-35.

67. Rouet P, Smih F, Jasin M. Expression of a site-specific endonuclease stimulates homologous recombination in mammalian cells. Proc Natl Acad Sci USA. 1994; 91: 6064-8.

68. Smih F, Rouet P, Romanienko PJ, Jasin M. Double-strand breaks at the target locus stimulate gene targeting in embryonic stem cells. Nucleic Acids Res. 1995; 23: 5012-9.

69. Lieber MR, Ma Y, Pannicke U, Schwarz K. Mechanism and regulation of human non-homologous DNA end-joining. Nat Rev Mol Cell Biol. 2003; 4: 712-20.

70. Santiago Y, Chan E, Liu PQ, Orlando S, Zhang L, Urnov FD, et al. Targeted gene knockout in mammalian cells by using engineered zinc-finger nucleases. Proc Natl Acad Sci USA. 2008; 105: 580914.

71. Geurts AM, Cost GJ, Freyvert Y, Zeitler B, Miller JC, Choi VM, et al. Knockout rats via embryo microinjection of zinc-finger nucleases. Science. 2009; 325: 433.

72. Doyon Y, McCammon JM, Miller JC, Faraji F, Ngo C, Katibah GE, et al. Heritable targeted gene disruption in zebrafish using designed zinc-finger nucleases. Nat Biotechnol. 2008; 26: 702-8.

73. Meng X, Noyes MB, Zhu LJ, Lawson ND, Wolfe SA. Targeted gene inactivation in zebrafish using engineered zinc-finger nucleases. Nat Biotechnol. 2008; 26: 695-701.

74. Carroll D. Genome engineering with targetable nucleases. Annu Rev Biochem. 2014; 83: 409-39.

75. Pâques F, Duchateau P. Meganucleases and DNA double-strand break-induced recombination: perspectives for gene therapy. Curr Gene Ther. 2007; 7: 49-66.

76. Stoddard BL. Homing endonucleases: from microbial genetic invaders to reagents for targeted DNA modification. Structure. 2011; 19: 7-15.

77. Porteus MH, Carroll D. Gene targeting using zinc finger nucleases. Nat Biotechnol. 2005; 23: 967-73.

78. Urnov FD, Rebar EJ, Holmes MC, Zhang HS, Gregory PD. Genome editing with engineered zinc finger nucleases. Nat Rev Genet. 2010; 11: 636-46.

79. Bogdanove AJ, Voytas DF. TAL effectors: customizable proteins for DNA targeting. Science. 2011; 333: 1843-6.

80. Scharenberg AM, Duchateau P, Smith J. Genome engineering with TAL-effector nucleases and alternative modular nuclease technologies. Curr Gene Ther. 2013; 13: 291-303. 
81. Certo MT, Morgan RA. Salient features of endonuclease platforms for therapeutic genome editing. Mol Ther. 2016; 24: 422-9.

82. Branzei D, Foiani M. Regulation of DNA repair throughout the cell cycle. Nat Rev Mol Cell Biol. 2008; 9: 297-308.

83. Valton J, Daboussi F, Leduc S, Molina R, Redondo P, Macmaster R, et al. 5'-Cytosine-phosphoguanine $(\mathrm{CpG})$ methylation impacts the activity of natural and engineered meganucleases. J Biol Chem. 2012; 287: 30139-50.

84. Kuhar R, Gwiazda KS, Humbert O, Mandt T, Pangallo J, Brault M, et $a l$. Novel fluorescent genome editing reporters for monitoring DNA repair pathway utilization at endonuclease-induced breaks. Nucleic Acids Res. 2014; 42: e4. doi: 10.1093/nar/gkt872.

85. Fu Y, Sander JD, Reyon D, Cascio VM, Joung JK. Improving CRISPR-Cas nuclease specificity using a modified guide RNA architecture. Nat Biotechnol. 2014; 32: 279-84.

86. Mali P, Aach J, Stranges PB, Esvelt KM, Moosburner M, Kosuri S, et al. CAS9 transcriptional activators for target specificity screening and paired nickases for cooperative genome engineering. Nat Biotechnol. 2013; 31: 833-8.

87. Ran FA, Hsu PD, Lin CY, Gootenberg JS, Konermann S, Trevino AE, et al. Double nicking by RNA-guided CRISPR Cas9 for enhanced genome editing specificity. Cell. 2013; 154: 1380-9.

88. Slaymaker IM, Gao L, Zetsche B, Scott DA, Yan WX, Zhang F. Rationally engineered Cas9 nucleases with improved specificity. Science. 2016; 351: 84-8.

89. Koo T, Lee J, Kim JS. Measuring and reducing off-target activities of programmable nucleases including CRISPR-Cas9. Mol Cells. 2015; 38: $475-81$.

90. Lanphier E, Urnov F, Haecker SE, Werner M, Smolenski J. Don’t edit the human germ line. Nature. 2015; 519: 410-1.

91. Carroll D. A perspective on the state of genome editing. Mol Ther. 2016; 24: 412-3.

92. Sternberg SH, Doudna JA. Expanding the biologist's toolkit with CRISPR-Cas9. Mol Cell 2015; 58: 568-74.

93. Gabriel R, von Kalle C, Schmidt M. Mapping the precision of genome editing. Nat Biotechnol. 2015; 33: 150-2.

94. Marraffini LA, Sontheimer EJ. CRISPR interference: RNA-directed adaptive immunity in bacteria and archaea. Nat Rev Genet. 2010; 11: $181-90$.

95. Deveau H, Garneau JE, Moineau S. CRISPR/Cas system and its role in phage-bacteria interactions. Annu Rev Microbiol. 2010; 64: 47593.

96. van der Oost J, Jore MM, Westra ER, Lundgren M, Brouns SJ. CRISPR-based adaptive and heritable immunity in prokaryotes. Trends Biochem Sci. 2009; 34: 401-7.

97. Terns MP, Terns RM. CRISPR-based adaptive immune systems. Curr Opin Microbiol. 2011; 14: 321-7.

98. Mali P, Esvelt KM, Church GM. Cas9 as a versatile tool for engineering biology. Nat Methods. 2013; 10: 957-63.

99. Zhang F, Wen Y, Guo X. CRISPR/Cas9 for genome editing: progress, implications and challenges. Hum Mol Genet. Hum Mol Genet. 2014; 23: R40-6.

100. Wu X, Kriz AJ, Sharp PA. Target specificity of the CRISPR-Cas9 system. Quantitative Biol. 2014; 2: 59-70.

101. Jinek M, East A, Cheng A, Lin S, Ma E, Doudna J. RNA-programmed genome editing in human cells. Elife. 2013; 2: e00471. doi: 10.7554/ eLife.00471.

102. Kearns NA, Genga RM, Enuameh MS, Garber M, Wolfe SA, Maehr R. Cas9 effector-mediated regulation of transcription and differentiation in human pluripotent stem cells. Development. 2014; 141: $219-23$
103. Kim JM, Kim D, Kim S, Kim JS. Genotyping with CRISPRCas-derived RNA-guided endonucleases. Nat Commun. 2014; 5: 3157. doi: $10.1038 /$ ncomms4157.

104. Kim S, Kim D, Cho SW, Kim J, Kim JS. Highly efficient RNAguided genome editing in human cells via delivery of purified Cas9 ribonucleoproteins. Genome Res. 2014; 24: 1012-9.

105. Rong Z, Zhu S, Xu Y, Fu X. Homologous recombination in human embryonic stem cells using CRISPR/Cas9 nickase and a long DNA donor template. Protein Cell. 2014; 5: 258-60.

106. Hwang WY, Fu Y, Reyon D, Maeder ML, Tsai SQ, Sander JD, et al. Efficient genome editing in zebrafish using a CRISPR-Cas system. Nat Biotechnol. 2013; 31: 227-9.

107. Koo Y, Ka D, Kim EJ, Suh N, Bae E. Conservation and variability in the structure and function of the Cas5d endoribonuclease in the CRISPR-mediated microbial immune system. J Mol Biol. 2013; 425: 3799-810.

108. Pennisi E. The CRISPR craze. Science. 2013; 341: 833-6.

109. Wilkinson R, Wiedenheft B. A CRISPR method for genome engineering. F1000Prime Rep. 2014; 6: 3. doi: 10.12703/P6-3.

110. Jiang W, Bikard D, Cox D, Zhang F, Marraffini LA. RNA-guided editing of bacterial genomes using CRISPR-Cas systems. Nature Biotech. 2013; 31: 233-9.

111. Gomaa AA, Klumpe HE, Luo ML, Selle K, Barrangou R, Beisel CL. Programmable removal of bacterial strains by use of genometargeting CRISPR-Cas systems. mBio. 2014; 5: e00928-13. doi: 10.1128/mBio.00928-13.

112. Bikard D, Jiang W, Samai P, Hochschild A, Zhang F, Marraffini LA. Programmable repression and activation of bacterial gene expression using an engineered CRISPR-Cas system. Nucleic Acids Res. 2013; 41: 7429-37.

113. Qi LS, Larson MH, Gilbert LA, Doudna JA, Weissman JS, Arkin AP, et al. Repurposing CRISPR as an RNA-guided platform for sequence-specific control of gene expression. Cell. 2013; 152: 1173-83.

114. Sampson TR, Weiss DS. Exploiting CRISPR/Cas systems for biotechnology. Bioessays. 2014; 36: 34-8.

115. Van der oost, Westra ER, Jackson RN, Wiedenheft B. Unraveling the structural and mechanistic basis of CRISPR-Cas systems. Nat Rev Microbiol. 2014; 12: 479-92.

116. Zentner GE, Henikoff S. High-resolution digital profiling of the epigenome. Nat Rev Genet. 2014; 15: 814-27.

117. Hilton IB, D'Ippolito AM, Vockley CM, Thakore PI, Crawford GE, Reddy TE, et al. Epigenome editing by a CRISPR-Cas9-based acetyltransferase activates genes from promoters and enhancers. Nat Biotechnol. 2015; 33: 510-7.

118. Kearns NA, Pham H, Tabak B, Genga RM, Silverstein NJ, Garber M, et al. Functional annotation of native enhancers with a Cas9-histone demethylase fusion. Nat Methods. 2015; 12: 401-3.

119. Zentner GE, Henikoff S. Epigenome editing made easy. Nat Biotechnol. 2015; 33: 606-7.

120. Lander ES. Initial impact of the sequencing of the human genome. Nature. 2011; 470: 187-97.

121. Cho SW, Kim S, Kim JM, Kim JS. Targeted genome engineering in human cells with the Cas9 RNA-guided endonuclease. Nat Biotechnol. 2013; 31: 230-2.

122. Hart T, Chandrashekhar M, Aregger M, Steinhart Z, Brown KR, MacLeod G, et al. High-resolution CRISPR screens reveal fitness genes and genotype-specific cancer liabilities. Cell. 2015; 163: 1515-26.

123. Prakash V, Moore M, Yanez-Munoz RJ. Current progress in therapeutic gene editing for monogenic diseases. Mol Ther. 2016; 24: $465-74$. 
124. DiCarlo JE, Norville JE, Mali P, Rios X, Aach J, Church GM. Genome engineering in Saccharomyces cerevisiae using CRISPRCas systems. Nucleic Acids Res. 2013; 41: 4336-43.

125. Li JF, Norville JE, Aach J, McCormack M, Zhang D, Bush J, et al. Multiplex and homologous recombination-mediated genome editing in Arabidopsis and Nicotiana benthamiana using guide RNA and Cas9. Nat Biotechnol. 2013; 31: 688-91.

126. Nekrasov V, Staskawicz B, Weigel D, Jones JD, Kamoun S. Targeted mutagenesis in the model plant Nicotiana benthamiana using Cas9 RNA-guided endonuclease. Nat Biotechnol. 2013; 31: 691-3.

127. Shan Q, Wang Y, Li J, Zhang Y, Chen K, Liang Z, et al. Targeted genome modification of crop plants using a CRISPR-Cas system. Nat Biotechnol. 2013; 31: 686-8.

128. Xie K, Yang Y. RNA-guided genome editing in plants using a CRISPR-Cas system. Mol Plant. 2013; 6: 1975-83.

129. Jiang W, Zhou H, Bi H, Fromm M, Yang B, Weeks DP. Demonstration of CRISPR/Cas $9 / \mathrm{sgRNA}$-mediated targeted gene modification in Arabidopsis, tobacco, sorghum and rice. Nucleic Acids Res. 2013; 41: e188. doi: 10.1093/nar/gkt780.

130. Wang H, Yang H, Shivalila CS, Dawlaty MM, Cheng AW, Zhang F, et al. One-step generation of mice carrying mutations in multiple genes by CRISPR/Cas-mediated genome engineering. Cell. 2013; 153: $910-8$

131. Shen B, Zhang J, Wu H, Wang J, Ma K, Li Z, et al. Generation of gene-modified mice via Cas9/RNA-mediated gene targeting. Cell Res. 2013; 23: 720-3.

132. Li D, Qiu Z, Shao Y, Chen Y, Guan Y, Liu M, et al. Heritable gene targeting in the mouse and rat using a CRISPR-Cas system. Nat Biotechnol. 2013; 31: 681-3.

133. Yang D, Xu J, Zhu T, Fan J, Lai L, Zhang J, et al. Effective gene targeting in rabbits using RNA-guided Cas9 nucleases. J Mol Cell Biol. 2014; 6: 97-9.

134. Nakayama T, Fish MB, Fisher M, Oomen-Hajagos J, Thomsen GH, Grainger RM. Simple and efficient CRISPR/Cas9-mediated targeted mutagenesis in Xenopus tropicalis. Genesis. 2013; 51: 835-43.

135. Yu Z, Ren M, Wang Z, Zhang B, Rong YS, Jiao R, et al. Highly efficient genome modifications mediated by CRISPR/Cas9 in Drosophila. Genetics. 2013; 195: 289-91.

136. Bassett AR, Tibbit C, Ponting CP, Liu JL. Highly efficient targeted mutagenesis of Drosophila with the CRISPR/Cas9 system. Cell Reports. 2013; 4: 220-8

137. Wang Y, Li Z, Xu J, Zeng B, Ling L, You L, et al. The CRISPR/Cas system mediates efficient genome engineering in Bombyx mori. Cell Res. 2013; 23: 1414-6.

138. Friedland AE, Tzur YB, Esvelt KM, Colaiácovo MP, Church GM, Calarco JA. Heritable genome editing in C. elegans via a CRISPRCas9 system. Nat Methods. 2013; 10: 741-3.

139. Choi PS, Meyerson M. Targeted genomic rearrangements using CRISPR/Cas technology. Nat Commun. 2014; 5: 3728. doi: $10.1038 /$ ncomms 4728

140. Chen C, Liu Y, Rappaport AR, Kitzing T, Schultz N, Zhao Z, et al. MLL3 is a haploinsufficient 7q tumor suppressor in acute myeloid leukemia. Cancer Cell. 2014; 25: 652-65.

141. Torres R, Martin MC, Garcia A, Cigudosa JC, Ramirez JC, RodriguezPerales S. Engineering human tumour-associated chromosomal translocations with the RNA-guided CRISPR- Cas9 system. Nat Commun. 2014; 5: 3964. 10.1038/ncomms4964.

142. Xue W, Chen S, Yin H, Tammela T, Papagiannakopoulos T, Joshi $\mathrm{NS}$, et al. CRISPR-mediated direct mutation of cancer genes in the mouse liver. Nature. 2014; 514: 380-4.
143. Heckl D, Kowalczyk MS, Yudovich D, Belizaire R, Puram RV, McConkey ME, et al. Generation of mouse models of myeloid malignancy with combinatorial genetic lesions using CRISPR-Cas9 genome editing. Nat Biotechnol. 2014; 32: 941-6.

144. Lombardo A, Genovese P, Beausejour CM, Colleoni S, Lee YL, Kim KA, et al. Gene editing in human stem cells using zinc finger nucleases and integrase-defective lentiviral vector delivery. Nat Biotechnol. 2007; 25: 1298-306

145. Cohen J, Pertsemlidis A, Kotowski IK, Graham R, Garcia CK, Hobbs HH. Low LDL cholesterol in individuals of African descent resulting from frequent nonsense mutations in PCSK9. Nat Genet. 2005; 37: 161-5.

146. Musunuru K, Pirruccello JP, Do R, Peloso GM, Guiducci C, Sougnez $\mathrm{C}$, et al. Exome sequencing, ANGPTL3 mutations, and familial combined hypolipidemia. N Engl J Med. 2010; 363: 2220-7.

147. Perez EE, Wang J, Miller JC, Jouvenot Y, Kim KA, Liu O, et al. Establishment of HIV-1 resistance in CD4+ T cells by genome editing using zinc-finger nucleases. Nat Biotechnol. 2008; 26: 80816.

148. Kennedy EM, Cullen BR. Bacterial CRISPR/Cas DNA endonucleases: A revolutionary technology that could dramatically impact viral research and treatment. Virology. 2015; 479-480: 213-20.

149. Bloom K, Ely A, Mussolino C, Cathomen T, Arbuthnot P. Inactivation of hepatitis B virus replication in cultured cells and in vivo with engineered transcription activator-like effector nucleases. Mol Ther 2013; 21: 1889-97.

150. Chen J, Zhang W, Lin J, Wang F, Wu M, Chen C, et al. An efficient antiviral strategy for targeting hepatitis B virus genome using transcription activator-like effector nucleases. Mol Ther. 2014; 22 303-11.

151. Cradick TJ, Keck K, Bradshaw S, Jamieson AC, McCaffrey AP. Zinc-finger nucleases as a novel therapeutic strategy for targeting hepatitis B virus DNAs. Mol Ther. 2010; 18: 947-54.

152. Weber ND, Stone D, Sedlak RH, De Silva Feelixge HS, Roychoudhury, $\mathrm{P}$, Schiffer JT, et al. AAV-mediated delivery of zinc finger nucleases targeting hepatitis B virus inhibits active replication. PLoS One. 2014; 9: e97579. doi: 10.1371/journal.pone.0097579.

153. Lin SR, Yang HC, Kuo YT, Liu CJ, Yang TY, Sung KC, et al. The CRISPR/Cas9 system facilitates clearance of the intrahepatic HBV templates in vivo. Mol Ther Nucleic Acids. 2014; 3: e186. doi: 10.1038/mtna.2014.38.

154. Dong C, Qu L, Wang H, Wei L, Dong Y, Xiong S. Targeting hepatitis $B$ virus cccDNA by CRISPR/Cas9 nuclease efficiently inhibits viral replication. Antiviral Res. 2015; 118: 110-7.

155. Kennedy EM, Bassit LC, Mueller H, Kornepati AV, Bogerd HP, Nie T, et al. Suppression of hepatitis B virus DNA accumulation in chronically infected cells using a bacterial CRISPR/Cas RNAguided DNA endonuclease. Virology. 2015; 476: 196-205.

156. Liu X, Hao R, Chen S, Guo D, Chen Y. Inhibition of hepatitis B virus by the CRISPR/Cas9 system via targeting the conserved regions of the viral genome. J Gen Virol. 2015; 96: 2252-61.

157. Grosse S, Huot N, Mahiet C, Arnould S, Barradeau S, Clerre DL, et al. Meganuclease-mediated inhibition of HSV1 infection in cultured cells. Mol Ther. 2011; 19: 694-702.

158. Bi Y, Sun L, Gao D, Ding C, Li Z, Li Y, et al. High-efficiency targeted editing of large viral genomes by RNA-guided nucleases. PLoS Pathog. 2014; 10: e1004090. doi: 10.1371/journal.ppat.1004090.

159. Aubert M, Boyle NM, Stone D, Stensland L, Huang ML, Magaret AS, et al. In vitro inactivation of latent HSV by targeted mutagenesis using an HSV-specific homing endonuclease. Mol Ther Nucleic Acids. 2014; 3: e146. doi: 10.1038/mtna.2013.75. 
160. Kennedy EM, Kornepati AV, Goldstein M, Bogerd HP, Poling BC, Whisnant $\mathrm{AW}$, et al. Inactivation of the human papillomavirus E6 or E7 gene in cervical carcinoma cells by using a bacterial CRISPR/ Cas RNA-guided endonuclease. J Virol. 2014; 88: 11965-72.

161. Couzin-Frankel J. Breakthrough of the year 2013. Cancer immunotherapy. Science. 2013; 342: 1432-33.

162. Miller JF, Sadelain M. The journey from discoveries in fundamental immunology to cancer immunotherapy. Cancer Cell. 2015; 27: 43949.

163. Boissel S, Jarjour J, Astrakhan A, Adey A, Gouble A, Duchateau P, et al. megaTALs: a rare-cleaving nuclease architecture for therapeutic genome engineering. Nucleic Acids Res. 2014; 42: 2591-601.

164. Provasi E, Genovese P, Lombardo A, Magnani Z, Liu PQ, Reik A, et al. Editing $\mathrm{T}$ cell specificity towards leukemia by zinc finger nucleases and lentiviral gene transfer. Nat Med. 2012; 18: 80715.

165. Torikai H, Reik A, Liu PQ, Zhou Y, Zhang L, Maiti S, et al. A foundation for universal T-cell based immunotherapy: $\mathrm{T}$ cells engineered to express a CD19-specific chimeric-antigen-receptor and eliminate expression of endogenous TCR. Blood. 2012; 119: 5697-705.

166. Berdien B, Mock U, Atanackovi D, Fehse B. TALEN-mediated editing of endogenous T-cell receptors facilitates efficient reprogramming of T lymphocytes by lentiviral gene transfer. Gene Ther. 2014; 21 : 539-48.

167. Sebastiano V, Maeder ML, Angstman JF, Haddad B, Khayter C, Yeo DT, et al. In situ genetic correction of the sickle cell anemia mutation in human induced pluripotent stem cells using engineered zinc finger nucleases. Stem Cells. 2011; 29: 1717-26.
168. Xie F, Ye L, Chang JC, Beyer AI, Wang J, Muench MO, et al. Seamless gene correction of $\beta$-thalassemia mutations in patientspecific iPSCs using CRISPR/Cas9 and piggyBac. Genome Res. 2014; 24: 1526-33.

169. Huang X, Wang Y, Yan W, Smith C, Ye Z, Wang J, et al. Production of gene- corrected adult beta globin protein in human erythrocytes differentiated from patient iPSCs after genome editing of the sickle point mutation. Stem Cells. 2015; 33: 1470-9.

170. Hoban MD, Cost GJ, Mendel MC, Romero Z, Kaufman ML, Joglekar $\mathrm{AV}$, et al. Correction of the sickle cell disease mutation in human hematopoietic stem/ progenitor cells. Blood. 2015; 125: 2597-604.

171. Chang CJ, Bouhassira EE. Zinc-finger nuclease-mediated correction of $\alpha$-thalassemia in iPS cells. Blood. 2012; 120: 3906-14.

172. Rio P, Baños R, Lombardo A, Quintana-Bustamante O, Alvarez L, Garate $\mathrm{Z}$, et al. Targeted gene therapy and cell reprogramming in Fanconi anemia. EMBO Mol Med. 2014; 6: 835-48.

173. Carroll D, Charo A. The societal opportunities and challenges of genome editing. Genome Biology. 2015; 16: 242. doi: 10.1186/ s13059-015-0812-0.

174. Baltimore D, Berg P, Botchan M, Carroll D, Charo RA, Church G, et al. A prudent path forward for genomic engineering and germline gene modification. Science. 2015; 348: 36-8.

175. Yin H, Xue W, Chen S, Bogorad RL, Benedetti E, Grompe M, et al. Genome editing with Cas9 in adult mice corrects a disease mutation and phenotype. Nat Biotechnol. 2014; 32: 551-3

176. Zhu Z, González F, Huangfu D. The iCRISPR platform for rapid genome editing in human pluripotent stem cells. Methods Enzymol. 2014; 546: 215-50.

177. Annas GJ. A "better baby" with gene editing? Cell. 2016; 165: 507-8. 